\title{
Modified T-Plate Interpositional Arthroplasty for Temporomandibular Joint Ankylosis: A New and Versatile Option
}

\author{
Imran Ahmad, Mohd Altaf Mir, Lalit Mohan Bariar \\ Department of Plastic and Reconstructive Surgery, Jawaharlal Nehru Medical College, Aligarh Muslim University, Aligarh, India
}

Background This study has been conducted with the aim of evaluating modified T-plate interpositional arthroplasty.

Methods A prospective comparative study in patients admitted with temporomandibular joint ankylosis. Ankylotic temporomandibular joint arthroplasty included condylectomy gap arthroplasty in 7, temporalis muscle flap interpositional arthroplasty in 8 , and modified T-plate interpositional arthroplasty in 13 cases. The patients were followed for three years. Collected data were tabulated and subjected to Fisher's exact test, chi-square test and probability estimation.

Results A significant increase in interincisal distance of $32 \mathrm{~mm}$ was seen in 12 (92.31\%) patients in the T-plate interposition group, in $2(25 \%)$ cases of the temporalis muscle flap interposition group, and in 1 case (14.28\%) of the condylectomy group at 12, 24, and 36 months. Re-ankylosis was observed in 1 case (9.69\%) of the T-plate interposition group, while as it was observed in $4(50 \%)$ cases in the temporalis muscle flap interposition group and 4 $(57.14 \%)$ cases in the condylectomy group, and these differences were statistically significant. Conclusions Our clinical experience with the use of the T-plate over the past 5 years has been encouraging, and our physiotherapy technique is quite simple. Even illiterate parents can assess it easily. Hence, we recommend this easy technique that does not damage the temporalis muscle for the management of temporomandibular joint ankylosis.

Keywords Temporomandibular joint / Arthroplasty / Ankylosis
Correspondence: Mohd Altaf Mir Department of Plastic and Reconstructive Surgery, Jawaharlal Nehru Medical College, Aligarh Muslim University, Aligar 202002, India

Tel: +91-70603-20658

Fax: +91-57127-20672

E-mail:draltafmir@gmail.com

Received: 12 Mar 2015 • Revised: 2 Jun 2015 • Accepted: 4 Jun 2015

pISSN: 2234-6163 • elSSN: 2234-6171 • http://dx.doi.org/10.5999/aps.2015.42.6.716 • Arch Plast Surg 2015;42:716-720

\section{INTRODUCTION}

Ankylosis means stiffness of a joint. Temporomandibular joint (TMJ) ankylosis leads to hypomobility of the said joint and a resultant decrease in mouth opening due to fibrous or bony fusion between the mandibular condyle and the glenoid cavity.

The cause of TMJ ankylosis or hypomobility may be within or external to the joint. Cases of intra-articular ankylosis usually occur unilaterally and are most frequently secondary to trauma. They mainly occur after untreated or maltreated childhood trauma leading to decreased mouth opening, facial disfigurement, and social awkwardness $[1,2]$.

TMJ ankylosis is managed by surgical modalities including gap and interpositional arthroplasty. However recurrence remains a challenge [3,4].

Condylectomy with gap arthroplasty is the basic technique for 
Fig. 1. Anatomical model of condylectomy and T-plate interpositional arthroplasty

Condylectomy has been performed (A) and a reshaped T-plate is fixed to the mandible for positioning between it and the glenoid cavity (B) as illustrated on this anatomical model of the temporomandibular joint.
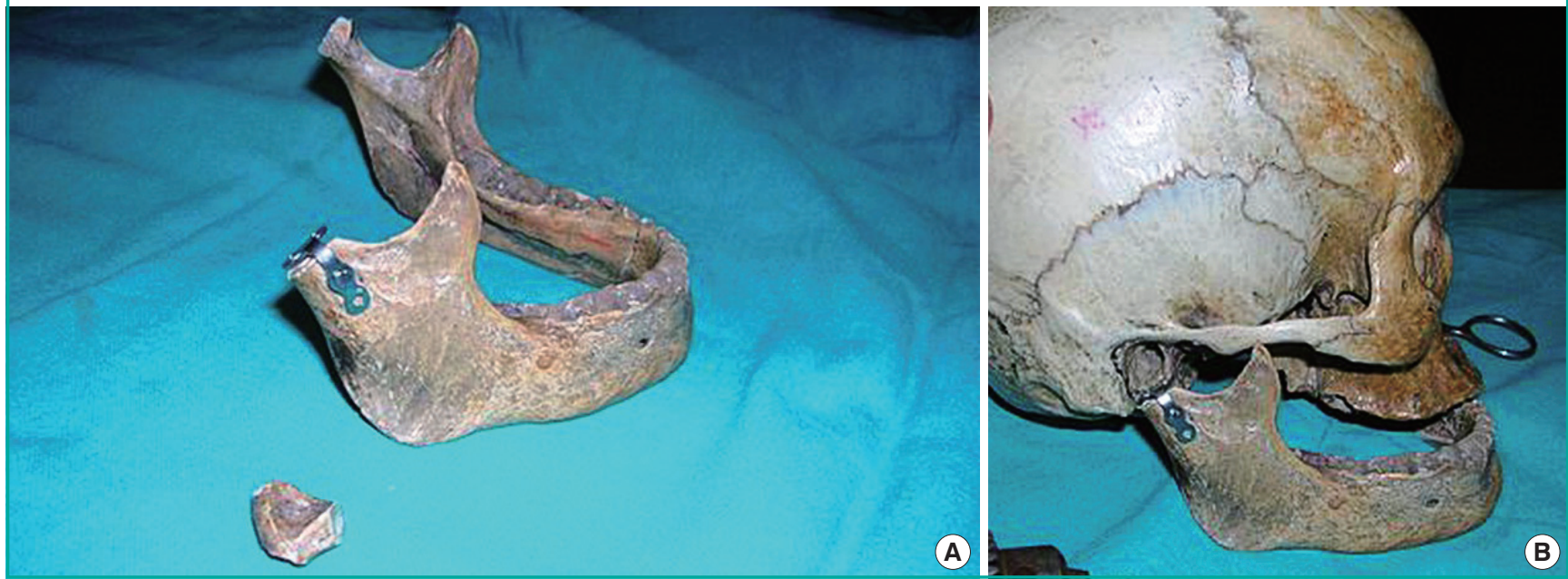

\section{Fig. 2. Four-hole T-plate bent to $90^{\circ}$}

A 4-hole T-plate is shown being bent to $90^{\circ}$ and reshaped such that its vertical limb can be fixed on the mandible after condylectomy and its bent limb can be interposed between the glenoid cavity and mandible.

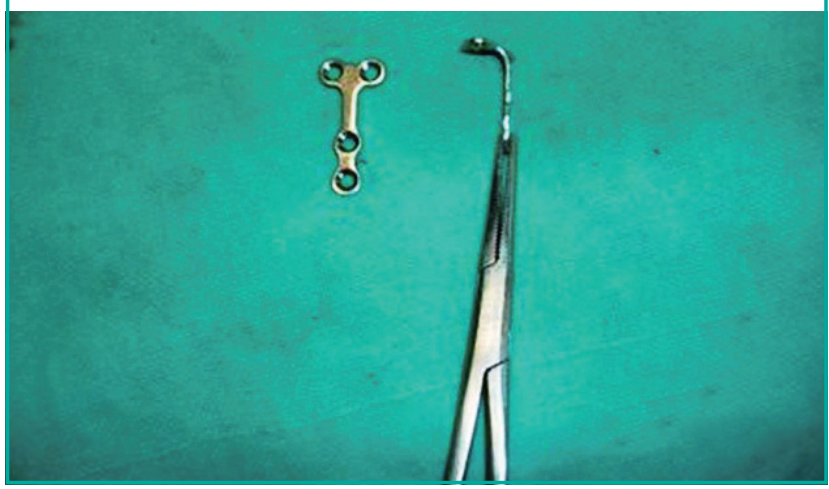

the treatment of adolescent and adult patients. We performed modified T-plate interpositional arthroplasty after condylectomy (Fig. 1) as a new modality of treatment for TMJ ankylosis to minimize recurrence, and compared it with temporalis muscle interpositional arthroplasty and condylectomy gap arthroplasty.

\section{METHODS}

The comparative study was conducted at our institution over a period of five years. The hypothesis made was that the modified T-plate interpositional arthroplasty we devised would be comparable to temporalis muscle interposition and condylectomy gap arthroplasty because the metal interposition prevents bony fusion. The study included 28 consecutive patients with TMJ
Fig. 3. Preauricular incision and modified T-plate arthroplasty

A preauricular incision is made to access the temporomandibular joint and then the reshaped T-plate is interposed after performing condylectomy.

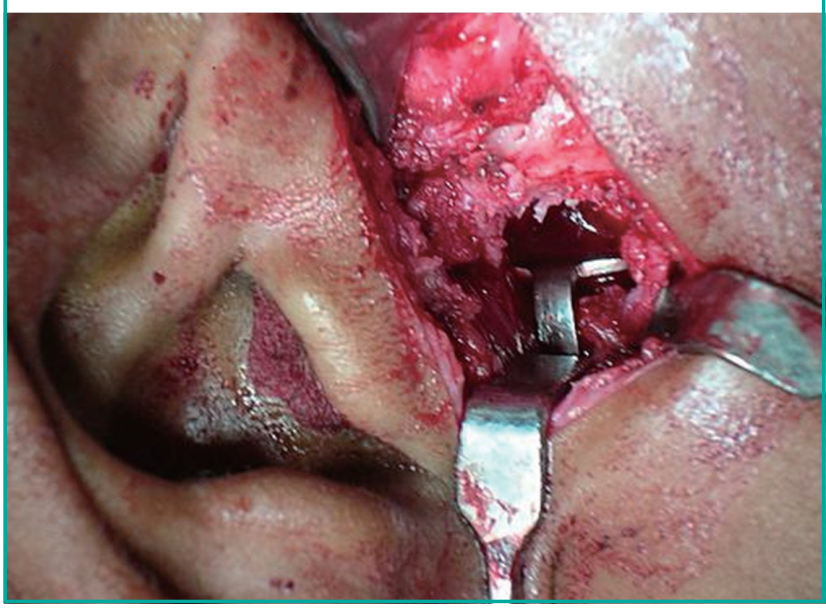

ankylosis who were admitted to the department of plastic surgery of our hospital over a period of five years. All these patients were evaluated by detailed history-taking and clinical examination and investigation. Ankylotic TMJ arthroplasty included the following: condylectomy gap arthroplasty in 7, temporalis muscle flap interpositional arthroplasty in 8 , and modified T-plate interpositional arthroplasty in 13 cases.

\section{Surgical technique}

The surgical technique of modified T-plate interpositional arthroplasty devised by the first author used pre-auricular incision (Figs. 2, 3) in all cases. After exposure of the TMJ, condylecto- 
my (measuring 1-1.5 cm) was carried out. A 4-hole T-plate was used, and it was fixed with screws to the ramus after bending it by $90^{\circ}$ at the upper end (Figs. 1-4). Then after achieving hemostasis, the skin flaps were closed.

Physiotherapy and assessment method: Active physiotherapy was started beginning on the first postoperative day. The patients were advised to insert wooden spoons between the upper and lower incisors. The number of the spoons was to be increased at regular intervals. The thickness of one wooden spoon used was around $1 \mathrm{~mm}$. This was an easy method to measure the mouth opening in millimeters as well as the effectiveness of the physiotherapy (Fig. 5). On each follow-up visit, a record was made of the amount of mouth opening in terms of the number of spoons the mouth could accommodate.

\section{RESULTS}

There was no statistical significance in the differences among the three groups of patients in terms of age (Table 1), sex (Table 2 ), and etiology of TMJ ankylosis ( $\mathrm{P}>0.05)$ (Table 3), but improvement in mouth opening was significant (Table 4), and the rate of complications and re-ankylosis after modified T-plate TMJ interposition arthroplasty was significantly lower (Table 5) as compared to condylectomy gap arthroplasty and temporalis muscle TMJ interpositional arthroplasty.

A significant increase in the interincisal distance of $32 \mathrm{~mm}$ was seen in $12(92.31 \%)$ patients in the T-plate interposition group (Figs. 5-7) and in 2 (25\%) cases of the temporalis muscle flap interposition group and 1 case (14.28\%) of the condylectomy group at 12, 24, and 36 months. Re-ankylosis was observed in 1 case $(9.69 \%)$ of the T-plate interposition group, while as it was observed in 4 (50\%) of the cases in the temporalis muscle flap

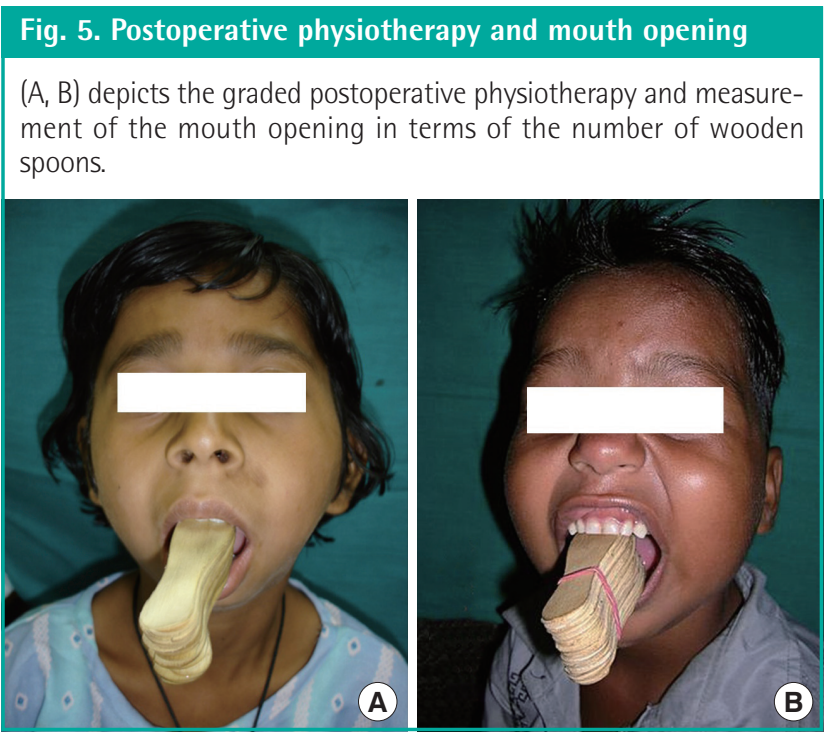

Fig. 4. Postoperative orthopantogram

A postoperative orthopantogram of a patient showing modified T-plate interpositional arthroplasty of the right temporomandibular joint (TMJ) (A) and a postoperative orthopantogram of a patient showing bilateral TMJ modified T-plate interposition (B).
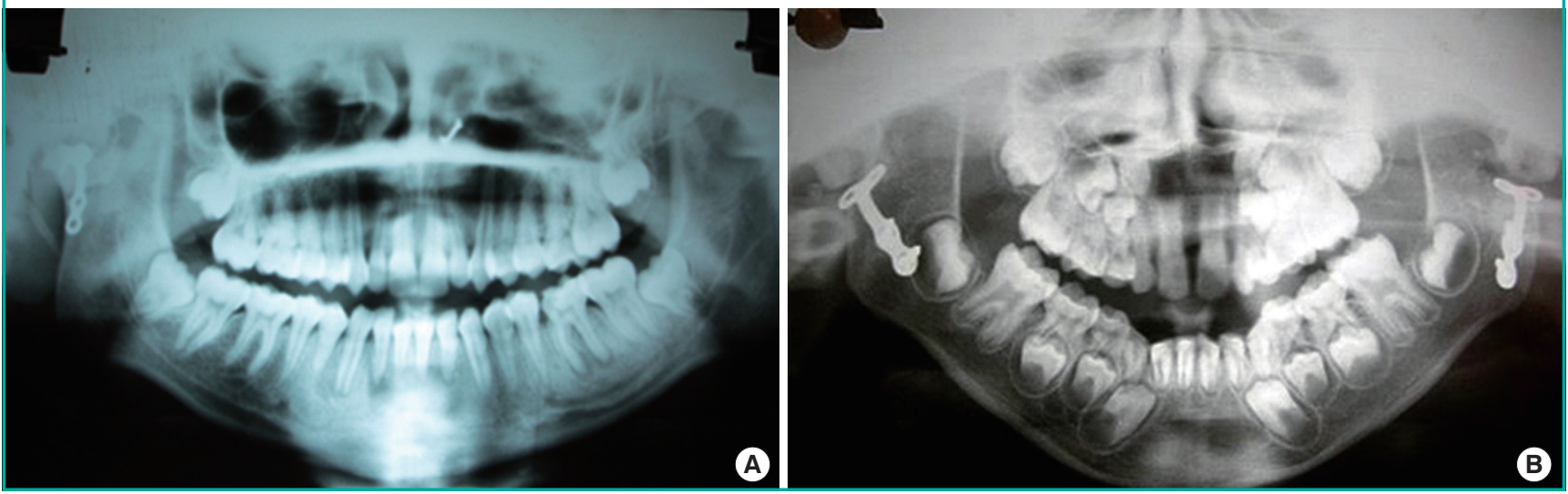

Table 1. Age distribution of patients

\begin{tabular}{|lccccc|}
\hline Age group (yr) & No. of patients & Percentage (\%) & $\begin{array}{c}\text { Condylectomy gap } \\
\text { arthroplasty (case) }\end{array}$ & $\begin{array}{c}\text { Temporalis muscle flap } \\
\text { interpositional } \\
\text { arthroplasty (case) }\end{array}$ & $\begin{array}{c}\text { Modified T-plate } \\
\text { interpositional } \\
\text { arthroplasty (case) }\end{array}$ \\
\hline $1-5$ & 3 & 10.71 & 1 & 1 & 1 \\
$6-10$ & 7 & 25 & 2 & 2 & 3 \\
$11-15$ & 18 & 64.29 & 4 & 5 & 9 \\
Total & 28 & 100 & 7 & 8 & 13 \\
\hline
\end{tabular}


Table 2. Gender distribution of patients

\begin{tabular}{|lccccc|}
\hline Sex & No. of cases & Percentage (\%) & $\begin{array}{c}\text { Condylectomy gap } \\
\text { arthroplasty (case) }\end{array}$ & $\begin{array}{c}\text { Temporalis muscle flap } \\
\text { interposition (case) }\end{array}$ & $\begin{array}{c}\text { T-plate interposition } \\
\text { (case) }\end{array}$ \\
\hline Male & 16 & 57.14 & 4 & 5 & 7 \\
Female & 12 & 42.86 & 3 & 3 & 6 \\
Total & 28 & 100 & 7 & 8 & 13 \\
\hline
\end{tabular}

Table 3. Etiological profile of temporomandibular joint ankylosis

\begin{tabular}{|lccccc|}
\hline Etiology & No. of cases & Percentage (\%) & $\begin{array}{c}\text { Condylectomy gap } \\
\text { arthroplasty (case) }\end{array}$ & $\begin{array}{c}\text { Temporalis muscle flap } \\
\text { interposition (case) }\end{array}$ & $\begin{array}{c}\text { T-plate interposition } \\
\text { (case) }\end{array}$ \\
\hline Trauma & 19 & 67.86 & 4 & 5 & 1 \\
Infection & 3 & 10.71 & 1 & 1 & 1 \\
Re-ankylosis & 6 & 21.43 & 2 & 2 & 2 \\
Total & 28 & 100 & 7 & 8 & 13 \\
\hline
\end{tabular}

Table 4. Mouth opening after the procedures

\begin{tabular}{|lcccc|}
\hline $\begin{array}{c}\text { Interincisal distance } \\
(\geq \mathbf{3 2} \mathbf{~ m m}) \text { at follow-up }\end{array}$ & $\begin{array}{c}\text { (A) Modified T-plate } \\
\text { interpositional } \\
\text { arthroplasty }(\mathbf{n = 1 3 )}\end{array}$ & $\begin{array}{c}\text { (B) Temporalis muscle } \\
\text { interpositional } \\
\text { arthroplasty }(\mathbf{n = 8})\end{array}$ & $\begin{array}{c}\text { (C) Condylectomy } \\
\text { gap arthroplasty } \\
(\mathbf{n}=\mathbf{7})\end{array}$ & $\begin{array}{c}\text { P-value } \\
\text { At } 12 \text { months }\end{array}$ \\
At 24 months & $12(92.31)$ & $2(25)$ & $1(14.28)$ & A vs. B=0.003 \\
At 36 months & $12(92.31)$ & $2(25)$ & $1(14.28)$ & A vs. C=0.001 (very significant) \\
\hline Values are presented as number (\%). & $12(92.31)$ & $2(25)$ & - \\
\hline
\end{tabular}

Table 5. Complications related to the procedures

\begin{tabular}{|lcccc}
\hline Complication & $\begin{array}{c}\text { (A) Modified T-plate } \\
\text { interpositional } \\
\text { arthroplasty }(\mathbf{n}=13)\end{array}$ & $\begin{array}{c}\text { (B) Temporalis muscle } \\
\text { interpositional } \\
\text { arthroplasty }(\mathbf{n}=8)\end{array}$ & $\begin{array}{c}\text { (C) Condylectomy gap } \\
\text { arthroplasty } \\
(\mathbf{n}=7)\end{array}$ & $\begin{array}{c}\text { P-value } \\
\text { Hematoma }\end{array}$ \\
Infection & $1(9.69)$ & $4(50)$ & $4(57.14)$ & A vs. B=0.047 \\
Re-ankylosis & $1(9.69)$ & $4(50)$ & $4(57.14)$ & Avs. C=0.030 (significant) \\
\hline Values are presented as number (\%). & & $4(50)$ & $4(57.14)$ & - \\
\hline
\end{tabular}

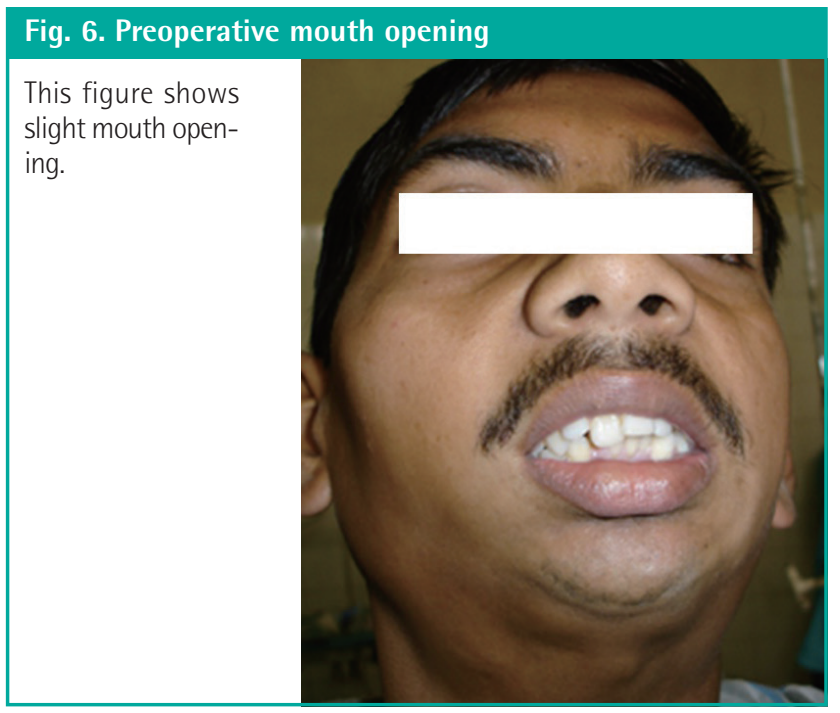

Fig. 7. Mouth opening after modified T-plate TMJ interpositional arthroplasty

In this figure, there is significant gain in the extent of mouth opening after performing modified Tplate temporomandibular joint (TMJ) interpositional arthroplasty.

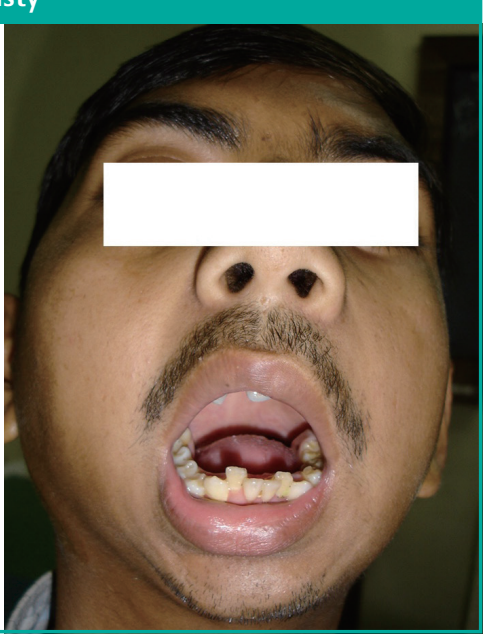


interposition group and 4 (57.14\%) of the cases in the condylectomy group; the differences among the groups were statistically significant.

\section{DISCUSSION}

TMJ ankylosis is more common in developing countries than in the developed world since there is better health care and health awareness in the people of the developed world [5]. It is most often post-traumatic in etiology during childhood, and leads to decreased mouth opening, facial deformity, and consequences of decreased mouth opening such as malnutrion $[1,2]$. The effective management of TMJ ankylosis depends on surgical therapy and compliance with physiotherapy [3]. There are three basic procedures for the management of TMJ ankylosis, namely, gap arthroplasty, interpositional arthroplasty, and joint reconstruction, which are associated with a higher incidence of recurrence compared to modified T-plate interpositional arthroplaty. Many authors have modified the procedures in order to decrease the rate of re-ankylosis [4]. Most authors tend to agree that recurrent ankylosis is less likely if material is interposed between the divided bone ends. The operative time and sophistication of the procedure along with morbidity at the donor and recipient sites have been reported after autogenous interpositional arthroplasty [6]. Alloplastic materials like Vitallium, tantalum, and Teflon, as well as acrylic and silastic or silicone rubber have also been used from time to time. Most studies have reported that the use of medical grade silicone has good long-term results, but infection, extrusion, and displacement have also been reported as complications of silicone implants $[7,8]$. Acrylic alloplastic material has been used as interposition material with encouraging results, but infection, extrusion, foreign body reactions, and problems of securing the graft in place have been noted, along with an additional procedure needed to prepare the acrylic graft [9-11].

Itanium meshes have also been used for reconstruction of TMJ [12]. We used a modified T-plate made of titanium as an interposition material and evaluated it against temporalis muscle interpositional arthroplasty and condylectomy gap arthroplasty. Statistically, a significantly greater change in mouth opening was seen in our cases treated with modified T-plate interpositional arthroplasty. We observed a significantly lower rate of recurrence because the metallic interposition between the two bony ends prevented the fusion of the bony ends. A significantly lower rate of other complications like infection and hematoma has been observed with three years of follow-up after using a modified T-plate as interpositional material in our study. In addition to the above advantages, the modified T-plate arthroplasty procedure avoids the donor site morbidity associated with temporalis muscle interpositional arthroplasty.

\section{REFERENCES}

1. He D, Yang C, Chen M, et al. Effects of soft tissue injury to the temporomandibular joint: report of 8 cases. Br J Oral Maxillofac Surg 2013;51:58-62.

2. Toyama M, Kurita K, Koga K, et al. Ankylosis of the temporomandibular joint developing shortly after multiple facial fractures. Int J Oral Maxillofac Surg 2003;32:360-2.

3. Khan Z. Management of temporomandibular joint ankylosis: literature review. Pakistan Oral Dent Jr 2005;25:151-55.

4. Tanrikulu R, Erol B, Gorgun B, et al. The contribution to success of various methods of treatment of temporomandibular joint ankylosis (a statistical study containing 24 cases). Turk J Pediatr 2005;47:261-5.

5. Akhtar MU, Abbas I, Ali Shah A. Use of silastic as interpositional material in the management of unilateral temporomandibular joint ankylosis. J Ayub Med Coll Abbottabad 2006;18:73-6.

6. Su-Gwan K. Treatment of temporomandibular joint ankylosis with temporalis muscle and fascia flap. Int J Oral Maxillofac Surg 2001;30:189-93.

7. Karaca C, Barutcu A, Baytekin C, et al. Modifications of the inverted T-shaped silicone implant for treatment of temporomandibular joint ankylosis. J Craniomaxillofac Surg 2004; 32:243-6.

8. Abbas I, Jamil M, Jehanzeb M, et al. Temporomandibular joint ankylosis: experience with interpositional gap arthroplasty at Ayub Medical College Abbottabad. J Ayub Med Coll Abbottabad 2005; 17:67-9.

9. Guven O. Treatment of temporomandibular joint ankylosis by a modified fossa prosthesis. J Craniomaxillofac Surg 2004; 32:236-42.

10. Erdem E, Alkan A. The use of acrylic marbles for interposition arthroplasty in the treatment of temporomandibular joint ankylosis: follow-up of 47 cases. Int J Oral Maxillofac Surg 2001;30:32-6.

11. Pitta MC, Wolford LM. Use of acrylic spheres as spacers in staged temporomandibular joint surgery. J Oral Maxillofac Surg 2001;59:704-6.

12. Mercuri LG, Edibam NR, Giobbie-Hurder A. Fourteen-year follow-up of a patient-fitted total temporomandibular joint reconstruction system. J Oral Maxillofac Surg 2007;65:1140-8. 